\title{
In situ fracture observations of distinct interface types within a fully lamellar intermetallic TiAl alloy
}

\author{
Michael Burtscher ${ }^{1, a)}$, Markus Alfreider ${ }^{1}$ (i), Klemens Schmuck ${ }^{1}$, Helmut Clemens ${ }^{2}$, \\ Svea Mayer ${ }^{2}$, Daniel Kiener ${ }^{1}$ (1) \\ ${ }^{1}$ Department of Materials Science, Chair of Materials Physics, Montanuniversität Leoben, Jahnstraße 12, Leoben 8700, Austria \\ ${ }^{2}$ Department of Materials Science, Chair of Physical Metallurgy and Metallic Materials, Montanuniversität Leoben, Roseggerstraße 12, Leoben 8700, \\ Austria

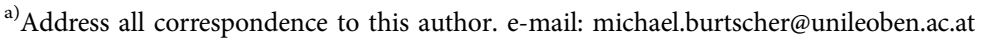

Received: 24 August 2020; accepted: 15 October 2020; published online: 5 February 2021

Intermetallic $\gamma$-TiAl-based alloys are commonly used as structural materials for components in high-temperature applications, although they generally suffer from a lack of ductility and crack resistance at ambient temperatures. Within this study, the process-adapted 4th generation $\mathrm{TNM}^{+}$alloy, exhibiting a fully lamellar microstructure, was examined using notched micro-cantilevers with defined orientations of lamellar interfaces. These configurations were tested in situ using superimposed continuous stiffness measurement methods during loading with simultaneous scanning electron microscopy observations. Subsequently, the video signal was used for visual crack length determination by computer vision and compared to values calculated from in situ changes in stiffness data. Applying this combinatorial approach enabled to determine the J-integral as a measure of the fracture toughness for microstructurally different local crack propagation paths. Thus, distinct differences in conditional fracture toughness could be determined from 3.7 MPa m $\mathrm{m}^{1 / 2}$ for $\gamma / \gamma$-interface to $4.4 \mathrm{MPa} \mathrm{m}^{1 / 2}$ for $a_{2} / \gamma$-interface.

\section{Introduction}

The use of intermetallic $\gamma$-TiAl-based alloys in aerospace and automotive applications, e.g., as turbine blades, inlet valves or turbocharger wheels, enables to enhance the efficiency and engine performance. This allows to reduce $\mathrm{CO}_{2}$ and $\mathrm{NO}_{x}$ emissions effectively $[1,2,3,4]$. The material's low density of $3.9-4.2 \mathrm{~g} / \mathrm{cm}^{3}$, which results in high-specific yield strength and specific Young's modulus, enables lightweight designs [2]. Up to temperatures of $800{ }^{\circ} \mathrm{C}, \gamma$-TiAl-based alloys exhibit good oxidation resistance and creep properties. However, they generally suffer from poor ductility and fracture toughness at room temperature $(\mathrm{RT})[2,5,6]$. Depending on chemical composition, the amount of impurities, applied heat treatments, phase fractions, and morphology of the present phases, fracture elongations of up to $5 \%$ have been measured in standardized tensile tests at RT $[5,7,8]$.

The process-adapted 4 th generation $\mathrm{TNM}^{+}$alloy, with a nominal composition of $\mathrm{Ti}-43 \mathrm{Al}-4 \mathrm{Nb}-1 \mathrm{Mo}-0.3 \mathrm{C}-0.3 \mathrm{Si}-0.1 \mathrm{~B}$ (in at.\%), solidifies via the $\beta-\mathrm{Ti}(\mathrm{Al})$ phase (disordered bodycentered cubic (bcc), A2 structure) and enables an almost texture-free cast microstructure $[2,9,10]$. To enhance the operating temperatures and improve the creep properties, the reduction of detrimental microstructural components by heat treatments is an effective method [11, 12]. The omission of the $\beta_{\mathrm{o}}$-TiAl phase (ordered bcc, B2 structure) and globular $\gamma$-TiAl grains $\left(\gamma_{\text {glob }}\right)$ (ordered face-centered tetragonal, $\mathrm{L} 1_{0}$ structure) results in a fully lamellar (FL) microstructure [9, $10,12,13,14]$. This is realized by solution annealing within the $\alpha-\mathrm{Ti}(\mathrm{Al})$ single-phase field region (disordered hexagonal, A3 structure) followed by a stabilization annealing slightly above the envisaged service temperature [9]. During these heat treatments, the chosen parameters influence grain size and lamellar spacing of the evolving $\alpha_{2} / \gamma$ colonies, as reported in Refs. $[10,13]$. In the course of this, at temperatures below $1175^{\circ} \mathrm{C}$, the $\alpha$-phase transforms to the ordered $\alpha_{2}-\mathrm{Ti}_{3} \mathrm{Al}$ phase (ordered hexagonal, $\mathrm{D}_{19}$ structure) due to short-range diffusion [2, 15]. The resultant FL microstructure is known to exhibit a superior combination of strength and creep properties but suffers from a lack of ductility [5, 9].

Nevertheless, in several studies, the formation of cracks along semicoherent $\alpha_{2} / \gamma$ interfaces is reported to take place due to the limited number of available glide systems $[16,17$, 
$18,19]$. This results in a preferred crack propagation along the aforementioned interface type due to local stress concentrations within $\alpha_{2} / \gamma$ colonies $[20,21,22,23,24]$. Macroscopic specimens exhibiting an FL microstructure generally attain higher fracture toughness and $J$-integral values. This is reasoned by the positive effect of colony boundaries and, consequently, the orientation of $\alpha_{2} / \gamma$ colonies with respect to the crack path $[16,21,25,26,27$, $28,29,30,31,32]$. Crack deflection, ligament bridging, pull-outs, mechanical twinning or slip in $\gamma$ lamellae and the development of microcracks in front of and parallel to the crack tip within colonies furthermore improve the fracture properties [27, 31, 33, 34]. Hence, misorientation between crack propagation direction and lamellar alignment is beneficial $[24,35,36]$. Furthermore, crack-tip blunting by ductile phases, shear ligament toughening, twinning, and crack-tip interface debonding are also considered to enhance the crack resistance at the micro-scale [12, 35, 37]. Therefore, the deformability of $\gamma$ lamellae due to mechanical twinning or slip of dislocations within the plastic zone in front of the crack tip and the interaction with adjacent $\gamma$ or $\alpha_{2}$ lamellae has to be considered [19, 21, 23, 32, 38, 39].

The current work aims to investigate the fracture behavior of lamellar interfaces of an FL $\gamma$-TiAl-based alloy and to determine the decisive factors on crack propagation at the microscale. These results are achieved by in situ testing of miniaturized notched cantilevers, whereby the pre-notches exhibit a distinct orientation and position concerning $\alpha_{2} / \gamma$ and $\gamma / \gamma$ interfaces, respectively. Using continuous stiffness measurement (CSM) and computer vision (CV), the crack length related to a specific displacement, the corresponding conditional fracture toughness $\left(K_{q}\right)$, and the $J$-integral were determined [21, 40, 41, 42]. This allows gaining fundamental knowledge of local processes as well as their interplay with different interface types within $\alpha_{2} / \gamma$ colonies as a basis for strategies to enhance the fracture resistance of $\mathrm{TiAl}$ alloys.

\section{Results}

The specimens exhibit distinct differences in mechanical response concerning their lamellar alignment and type of tested
TABLE 1: Summary of the tested cantilevers including their dimensions [see Fig. 1(b)], orientation dependency of the $a_{2} / \gamma$ interfaces to the expected crack plane (type (II) or (L)) and deviation angle $\varphi$ of $a_{2} / \gamma$ lamellae to the desired orientation.

\begin{tabular}{lcccccr}
\hline \hline & $\begin{array}{c}W \\
(\mu \mathrm{m})\end{array}$ & $\begin{array}{c}B \\
(\mu \mathrm{m})\end{array}$ & $\begin{array}{c}a_{\mathrm{c}} \\
(\mu \mathrm{m})\end{array}$ & $\begin{array}{c}L_{\mathrm{c}} \\
(\mu \mathrm{m})\end{array}$ & $\begin{array}{c}L \\
(\mu \mathrm{m})\end{array}$ & $\begin{array}{c}\boldsymbol{\varphi} \\
\left({ }^{\circ}\right)\end{array}$ \\
\hline (II)_C1 & 2.67 & 2.15 & 0.945 & 12.10 & 12.99 & 7.7 \\
(II)_C2 & 3.07 & 2.59 & 0.876 & 13.76 & 15.50 & 7.7 \\
(II)_C3 & 2.46 & 2.72 & 0.966 & 12.14 & 13.58 & -7.7 \\
(II)_C4 & 2.55 & 2.74 & 0.889 & 9.67 & 11.37 & 7.7 \\
(II)_C5 & 2.59 & 2.82 & $-^{\mathrm{a}}$ & $-^{\mathrm{a}}$ & 11.39 & -7.7 \\
(L)_C1 & 2.54 & 2.23 & 0.816 & 13.09 & 15.95 & 0.3 \\
(L)_C1 & 2.71 & 2.29 & 1.056 & 11.80 & 14.39 & 0.3 \\
\hline \hline
\end{tabular}

The accuracy of the measurements was determined to be $\pm 0.02 \mu \mathrm{m}$, representing the maximum standard deviation of at least four individual length measurements for each dimension.

${ }^{a}$ Unnotched cantilever.

interface. Thus, in the following, cantilevers exhibiting perpendicular and parallel $\alpha_{2} / \gamma$ interfaces regarding their presumed crack plane are discussed separately. The specimen positions and orientations were chosen in a way that the lamellar structure of the $\alpha_{2} / \gamma$ colonies is aligned either perpendicular (type (L)) or parallel (type (II)) to the assumed crack propagation plane of the cantilevers [see Fig. 1(c)]. The dimensions of the fabricated cantilevers and their orientation to the containing grains are listed in Table 1.

\section{Continuous stiffness measurement}

The measured force- and dynamic compliance-displacement data from in situ experiments are displayed for (II)_C2 specimen in Fig. 2(a). Due to the high scanning speed, varying stages of crack development can be differentiated. Here, position (1) marks the initial state at the beginning of data recording. The corresponding SE images are displayed in Fig. 2(b). Position (2) indicates the last data point before unstable crack growth arises. This event is accompanied by a drastic decrease in force and an increase in compliance as well as displacement. In position (3) the crack arrests, followed by a stable dynamic compliance with increasing force, suggesting again elastic
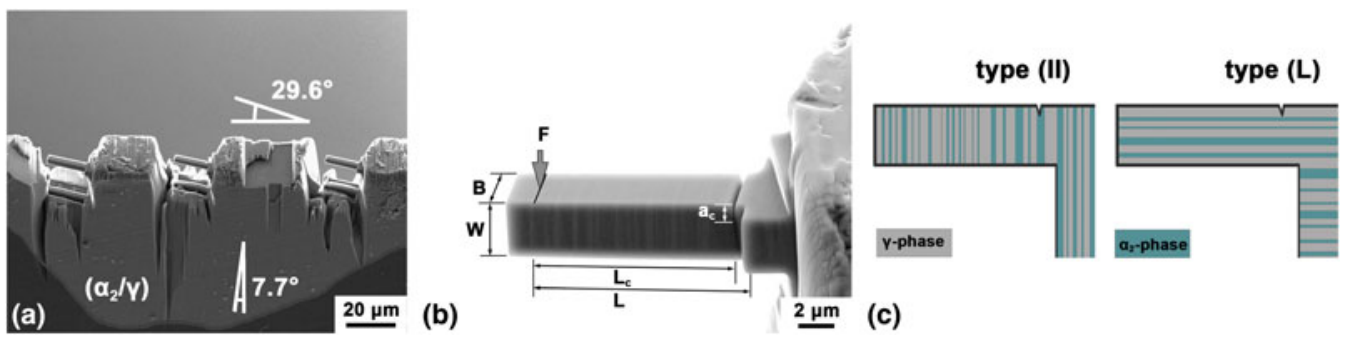

Figure 1: (a) Overview of three cantilevers with an angle of $29.6^{\circ}$ to the hosting sample taken in the scanning electron microscope (SEM) with secondary electron (SE) contrast. The original $a_{2} / \gamma$ colony is visible in BSE contrast and highlighted with gray contrast for better visibility. (b) SEM-SE side view of a notched TNM ${ }^{+}$ cantilever with designated $a_{2}$ and $\gamma$ lamellae parallel to the expected crack propagation plane. (c) Sketches of the two different cantilever types, including their lamellar orientation of $a_{2}$ and $\gamma$-phase as tested herein. 

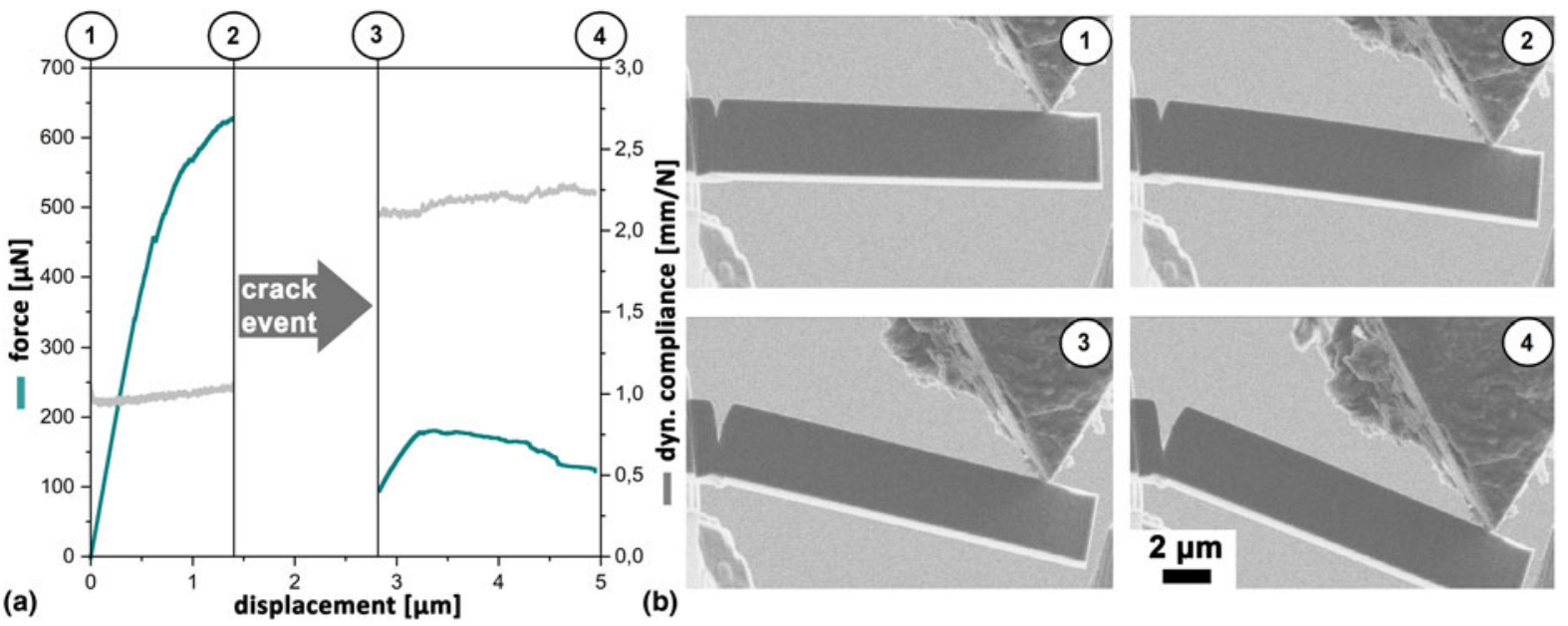

Figure 2: (a) Measured force- and dynamic compliance over displacement data, determined during the in situ CSM experiment of (II)_C2 cantilever within the SEM. The gap between (2) and (3) indicates unstable crack growth along an $a_{2} / \gamma$ interface. In (b), selected frames of the recorded video depict the evident states: (1) prior loading, (2) directly before unstable crack growth, (3) directly after unstable crack growth, and (4) at the end of the in situ experiment are shown.

loading at the crack tip. Thereafter, the force continues to gradually decrease, while the dynamic compliance increases, suggesting again crack propagation up to a maximum displacement of $5 \mu \mathrm{m}$ at position (4).

As described in the experimental part, the continuous stiffness is calculated from the inverse of the dynamic compliance. Furthermore, it is used for crack length and J-integral determination, which is described in detail in the "Methodology" section.

\section{Fracture parameter}

The determined force-displacement and J-integral over crack length data of tested cantilevers from type (II) with predominant interlamellar crack growths are displayed in Figs. 3(a) and $3(\mathrm{~b})$, respectively. The specimens witnessed drastic drops in force-displacement data, correlating to sudden unstable crack events along the respective interfaces. However, also minor force drops without simultaneous crack propagation are visible in Fig. 3(a) during early loading, indicating twinning or dislocation movements on activated glide systems [21, 23, 43]. Finally, a drastic force drop accompanied by extensive crack elongation indicates interface cleavage followed by the termination of the experiment. Determined $J$-integral values were calculated according to Eq. (3), as detailed in the data evaluation and analysis part.

The fracture parameters at final fracture or in the presence of a primary crack event are listed in Table 2, whereas $K_{\mathrm{q}}$ and conditional fracture toughness from the $J$-integral $\left(K_{\mathrm{q}, j}\right)$ are calculated from Eqs. (2) and (6), respectively. The listed $K_{\mathrm{q}}$ values are calculated in the stable crack propagation regime prior to unstable crack events and constitute therefore the conditional
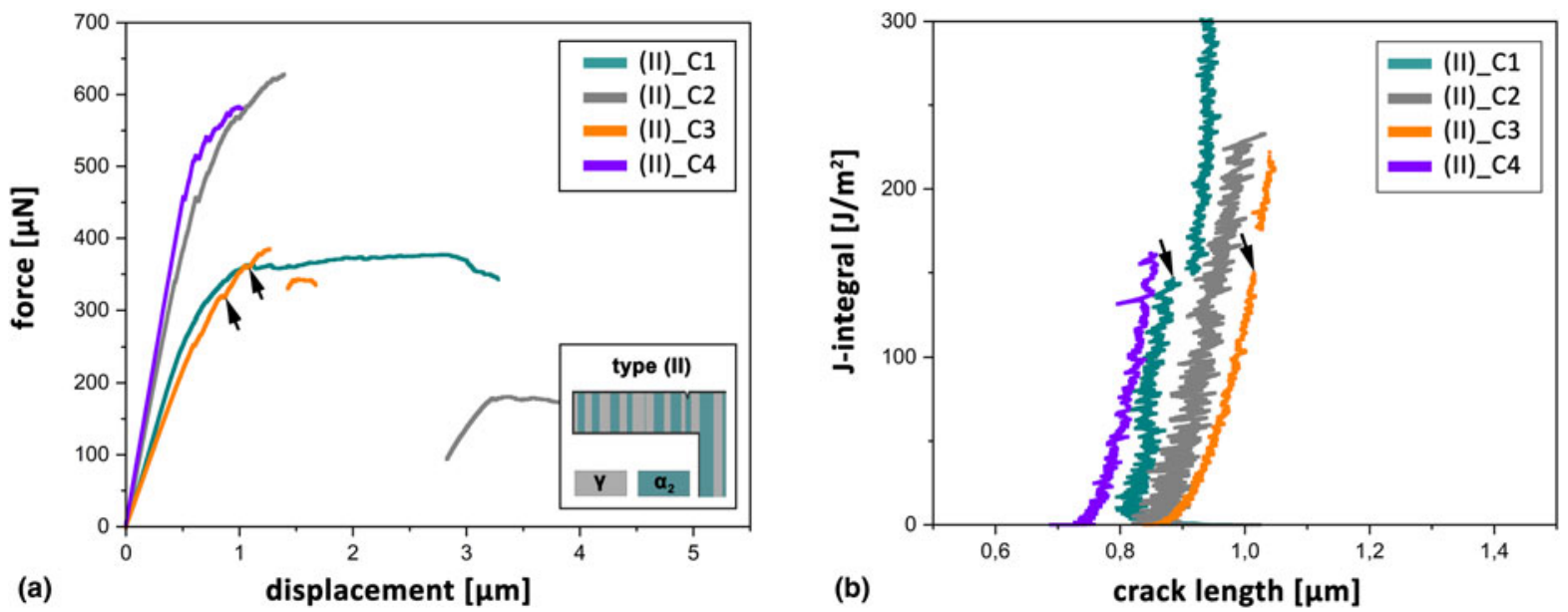

Figure 3: (a) Force-displacement and (b) J-integral over crack length data from micro-cantilever experiments with parallel orientation of the tested interfaces to the notch. Black arrows indicate minor force drops in (a) and non-fatal fracture events in (b). 
TABLE 2: Calculated fracture toughness and $J$-integral $(J)$ values of tested cantilevers.

\begin{tabular}{llclllr}
\hline \hline & $\begin{array}{l}\text { Interface } \\
(-)\end{array}$ & $\begin{array}{c}K_{\mathrm{q}} \\
(\mathrm{MPa} \sqrt{\mathrm{m}})\end{array}$ & $\begin{array}{l}J_{\mathrm{el}} \\
\left(\mathrm{J} / \mathrm{m}^{2}\right)\end{array}$ & $\begin{array}{l}J_{\mathrm{pl}} \\
\left(\mathrm{J} / \mathrm{m}^{2}\right)\end{array}$ & $\begin{array}{l}J \\
\left(\mathrm{~J} / \mathrm{m}^{2}\right)\end{array}$ & $\begin{array}{r}K_{\mathrm{q}, j} \\
(\mathrm{MPa} \sqrt{\mathrm{m}})\end{array}$ \\
\hline (II)_C1 & $\gamma$ & 3.4 & 57 & 88 & 145 & 5.4 \\
& $\gamma / \gamma$ & 3.5 & 61 & 492 & 553 & 10.5 \\
(II)_C2 & $\mathrm{a}_{2} / \gamma$ & 4.4 & 98 & 130 & 228 & 6.8 \\
(II)_C3 & $\mathrm{a}_{2}$ & 3.6 & 64 & 85 & 149 & 5.4 \\
& $\mathrm{a}_{2} / \gamma+\mathrm{a}_{2}$ & 3.2 & 52 & 165 & 217 & 6.5 \\
(II)_C4 & $\gamma / \gamma+\gamma_{g l o b}$ & 3.7 & 64 & 98 & 162 & 5.6 \\
(L)_C1 & $\gamma / \gamma$ & 3.3 & 57 & 134 & 191 & 5.9 \\
(L)_C2 & $\gamma / \gamma$ & 3.7 & 72 & 97 & 169 & 5.5 \\
\hline \hline
\end{tabular}

In the case of the specimen (II)_C1 and (II)_C3, two data sets are given for the primary translamellar fracture event of a single lamella and final fracture along different interfaces, respectively. In the case of the (II) _C4 specimen, $\gamma_{\text {glob }}$ indicates an additional globular $\gamma$ grain along the crack path. The given values of type (L) cantilevers correspond to the first significant drops in force-displacement data. Their positions are marked in Fig. 4 by black arrows. Tested interfaces are defined as $\gamma / \gamma$, indicating solely perpendicular $\gamma$ lamellae in the tested specimen volume.

fracture toughness. Relating parameters were determined at the corresponding position of $K_{\mathrm{q}}$. The elastic and plastic parts of the $J$-integral are determined according to Eqs. (4) and (5) and are displayed as $J_{\mathrm{el}}$ and $J_{\mathrm{pl}}$. Furthermore, the tested interface types were validated by post-mortem SEM investigations and, therefore, constitute the actual tested interfaces.

In addition to type (II) specimens, cantilevers with their expected crack plane perpendicular to the lamellar direction were tested (type (L)). This experimental setup was suggested to result in translamellar crack propagation and corresponding force-displacement curves are displayed in Fig. 4. Backscattered electron (BSE) images of type (L) cantilevers showed merely $\gamma$ lamellae with different $\gamma / \gamma$ interfaces along the cantilevers section. Thus, a Young's modulus of $180.6 \mathrm{GPa}$ was calculated with the Voigt model taking into account the strong anisotropy of elastic constants in the $\gamma$-phase [44]. The determined maximum forces at the base of type (L) cantilevers are notably lower compared to type (II) cantilevers. However, substantiated in the absence of the $\alpha_{2}$-phase, a quite ductile specimen behavior was determined. The determination of fracture parameters was implemented correspondingly to the case of type (II) cantilevers. Therefore, calculated $K_{\mathrm{q}}$ and $J$-integral values of type (L) cantilevers are listed in Table 2. Due to the absence of unstable crack events, the positions of drastic force drops were used for the determination of $K_{\mathrm{q}}$ (black arrows in Fig. 4). Owing to the absence of $\alpha_{2}$ lamellae within the tested cantilevers, the interface type was defined as $\gamma / \gamma$ interfaces.

\section{Crack propagation and fracture analysis}

In the case of the (II)_C1 specimen, the notch was introduced within a broad $\gamma$ lamella, and therefore, two different crack

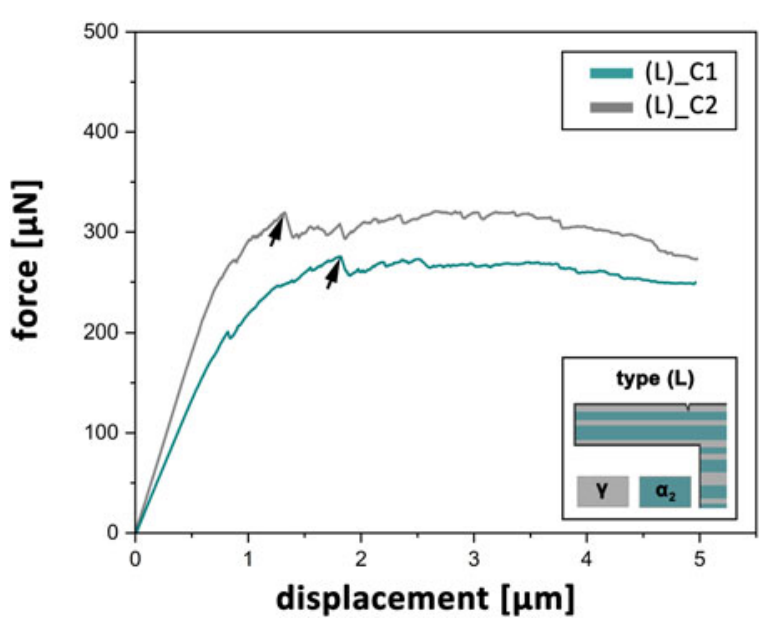

Figure 4: Force-displacement data of cantilevers exhibiting their expected crack propagation plane perpendicular to the $a_{2} / \gamma$ lamellae. Therein, distinct force drops without simultaneous crack growth are marked by arrows, indicating the positions of respective data points from Table 2 .

events were identified by fracture analysis and CSM determination [Fig. 5(a)]. Prior to the first event, the crack propagated translamellar through the massive $\gamma$ lamella. At a $J$-integral value of $145 \mathrm{~J} / \mathrm{m}^{2}$, a minor discontinuity with a simultaneous crack growth of $31 \mathrm{~nm}$ is marked in Fig. 3(b) by an arrow. At this point, the translamellar failure of the narrow $\gamma$ lamella is assumed to take place [black arrow in SEM-SE image, Fig. 5(a)] and indicates the first crack event. According to Eq. (2), the determined $K_{\mathrm{q}}$ amounts to 3.4 MPa $\sqrt{ } \mathrm{m}$ for the failure of the $\gamma$ lamellae.

During the second crack event, interlamellar crack propagation along different $\gamma / \gamma$ interfaces took place. Here, the $J$-integral reached a maximum value of $553 \mathrm{~J} / \mathrm{m}^{2}$ upon considerable crack propagation of $512 \mathrm{~nm}$, according to CSM determination. During in situ testing, shearing and final tearing of a ligament were observed in the SEM video, as reported in Ref. [23]. This ligament constitutes part of a failed $\gamma$ lamella which is marked by white arrows in Fig. 5(a) and outlined in the sketch by splitting the fracture path. Using Eq. (6), $K_{\mathrm{q}, j}$ values of 5.4 and $10.5 \mathrm{MPa} \sqrt{ } \mathrm{m}$ were determined for the translamellar failure of a single $\gamma$ lamella and final interlamellar crack growth along $\gamma / \gamma$ interfaces, respectively [18]. Furthermore, solely the share of $J_{\mathrm{pl}}$ increased from the first to second fracture event (Table 2). This indicates severe effects from plastic deformation, again evidenced by the formation of a distinct plastic zone at the bottom side of the cantilever. Along the fractured surface in Fig. 5(a), this plastic zone is visible as an undefined fractured zone, which was additionally enhanced during the fatal bending in the aftermath of the experiment.

The second specimen (II)_C2 was notched near an $\alpha_{2} / \gamma$ interface and failed at higher force but lower displacement values compared to the (II)_C1 specimen. The crack propagation 

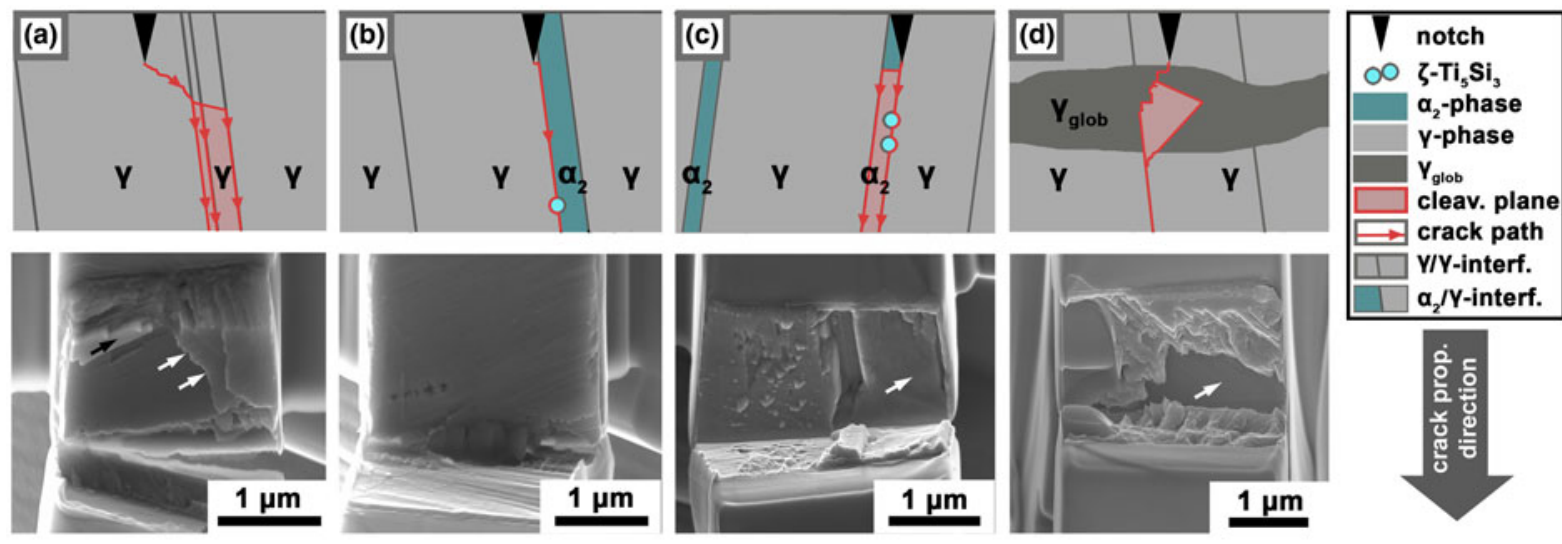

crack path

$\mathbf{a}_{2} / \mathrm{Y}$-interf.

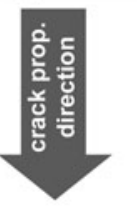

Figure 5: Sketch of the observed crack path along different interface types as well as a side view of the cantilever (top) and SEM-SE images of the corresponding fractured surfaces (bottom) are displayed. (a), The fracture along a $\gamma / \gamma$ interface, (b) an $a_{2} / \gamma$ interface, (c) an $a_{2} / \gamma$ interface as well as an $a_{2}$ lamella, and (d) the simultaneous crack propagation along a globular $\gamma$ grain and $\gamma / \gamma$ interface are depicted. Arrows indicate cleaved interfaces as described in detail within the respective section.

was determined to be constant during the first segment of loading [see Fig. 7(a)]. The determined $K_{\mathrm{q}}$ value at the onset of fatal fracture of $667 \mathrm{~nm}$ amounts to $4.4 \mathrm{MPa} \sqrt{ } \mathrm{m}$ and, therefore, constitutes the highest measured value in this study. The calculated $J$-integral raised to $228 \mathrm{~J} / \mathrm{m}^{2}$ before the first unstable crack propagation and is significantly higher compared to the first fracture event of (II)_C1 specimen along a $\gamma$ interface. Here, the elastic and plastic share of the measured J-integral are both equally elevated in contrast to the first fracture event of (II)_C2 specimen. Afterward, the crack was decelerated by the combined effect of crack deflection at $\zeta-\mathrm{Ti}_{5} \mathrm{Si}_{3}$ silicide particles and minor plastic zone formation at the bottom side of the cantilever. These particles were pulled out of the $\gamma$ interface and stuck within the $\alpha_{2}$ lamella [Fig. 5(b)]. Due to the strong affinity of Si to Ti and the $\alpha_{2}$-phase, their globular shape and position along the interface, these particles are assumed to be $\zeta-\mathrm{Ti}_{5} \mathrm{Si}_{3}$ silicides as reported in Refs. [9, 45].

The force-displacement curve of the (II)_C3 specimen behaves similarly to the already discussed (II)_C2 specimen, despite the deviation angle $\varphi$ pointing toward the opposite direction. This is explained by the fact that the (II)_C3 and (II)_C5 cantilevers were fabricated mirror-inverted to enable higher occupancy within the limited extent of the selected $\alpha_{2} / \gamma$ colony. Again, the fractured surface unveiled numerous $\zeta-\mathrm{Ti}_{5} \mathrm{Si}_{3}$ particles and also a part from an $\alpha_{2}$ lamella could be identified. Due to the presumed strengthening effect of $\zeta-\mathrm{Ti}_{5} \mathrm{Si}_{3}$ silicide particles on the $\alpha_{2} / \gamma$ interface, the crack was forced to propagate through the enclosed $\alpha_{2}$ lamella to the facing $\alpha_{2} / \gamma$ interface exhibiting no strengthening particles [Fig. 5 (c), white arrow]. This may be the reason of the lower maximum force level and consequent lower $K_{\mathrm{q}}$ value of 3.4 MPa $\sqrt{ } \mathrm{m}$ of this cantilever [Fig. 3(a)] [46]. As already observed in Fig. 3(b), the major amount of these particles remained on the $\alpha_{2}$ interface. A study regarding the interface structure of $\zeta-\mathrm{Ti}_{5} \mathrm{Si}_{3}$ particles within the $\gamma$-phase unveiled inand semicoherent interface types to be cleaved [47]. Therefore, different interface types and orientation relationships between the $\gamma$-phase and polygonal or needle-shaped $\zeta-\mathrm{Ti}_{5} \mathrm{Si}_{3}$ particles were reported and may contrary influence the cleavage energy. During in situ testing, initially steady crack growth was determined by CSM until a $J$-integral of $149 \mathrm{~J} / \mathrm{m}^{2}$. Then, sudden crack propagation of $11 \mathrm{~nm}$ could be observed [Fig. 3(b)]. This first crack event was presumably linked to the delamination of the $\alpha_{2}$ lamella segment. Afterward, the crack again propagated steadily for $17 \mathrm{~nm}$ to a $J$-integral of $217 \mathrm{~J} / \mathrm{m}^{2}$, followed by a second crack event
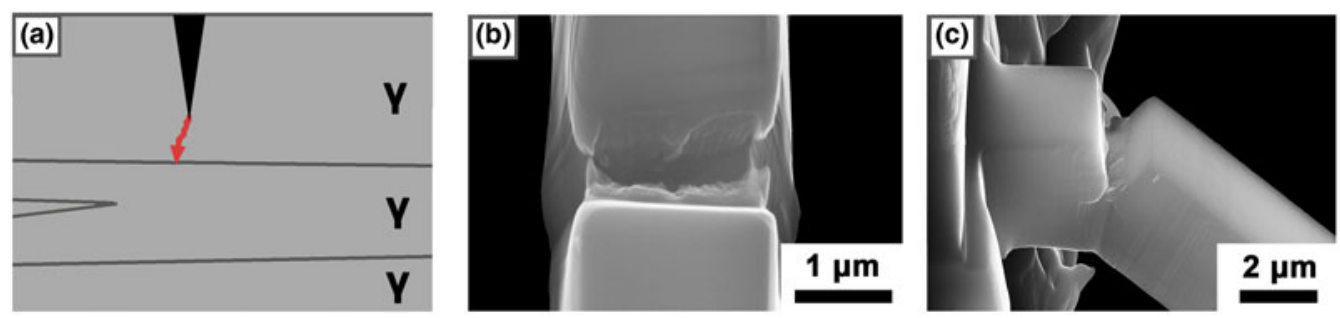

Figure 6: For specimen (L)_C1 (a) a sketch of the observed crack path through $\gamma$ lamellae with (b) the corresponding fractured surface and (c) a side view showing the crack path are displayed. Since the type (L) cantilevers were located at the same position within the $a_{2} / \gamma$ colony, corresponding lamellae were tested and only one representative sketch and fractured surface are displayed. 

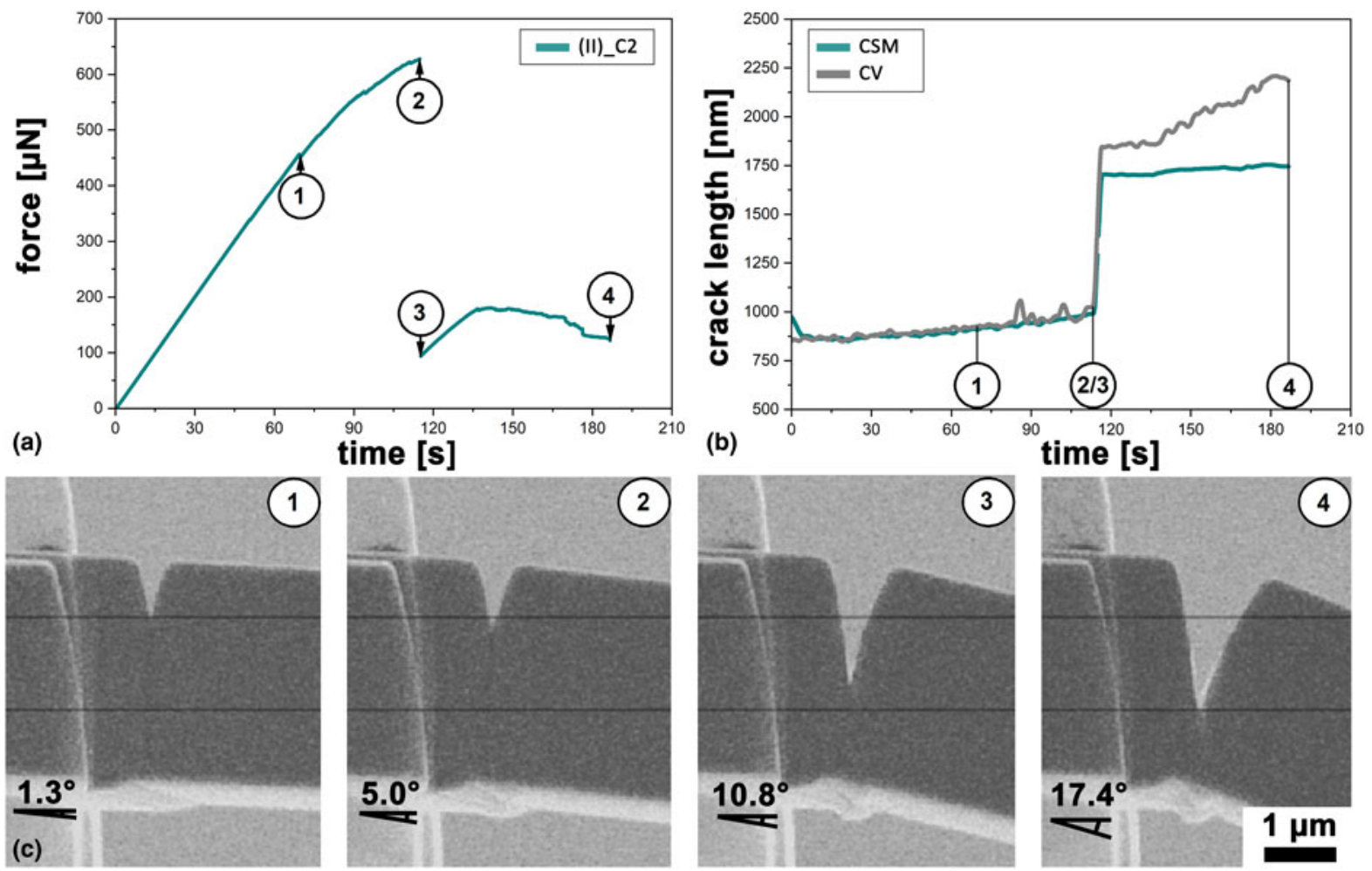

Figure 7: (a) Force-time data and (b) crack length-time data, determined by CSM and CV, of the (II)_C2 cantilever are displayed. Furthermore, positions from 1-4 marked in (a) and (b) correspond to the detailed SEM images in (c). These micrographs represent side-view snapshots of the in situ SEM video and contain two horizontal lines to highlight crack growth during the experiment. Given angles indicate the bending angle in contrast to the unloaded cantilever.

extending $665 \mathrm{~nm}$. According to in situ observations and fracture analysis, the $\alpha_{2} / \gamma$ interface and the $\alpha_{2}$ lamella were cleaved during this fracture event. Hence, the strengthening effect of the particles at the $\alpha_{2} / \gamma$ interface forced the crack to the opposing interface and consequently the $\alpha_{2}$ lamella cleaved. This is substantiated by observations of Heatherly et al. [48] who identified the cleavage of $\alpha_{2}$ lamellae as a primary failure mechanism within $\alpha_{2} / \gamma$ colonies. On the right-hand side of the fractured surface in Fig. 3(c), the cleaved $\alpha_{2}$ lamella is encountered.

The notch in the (II)_C4 cantilever was located within a coarse $\gamma$ lamellae and the specimen also contains an elongated globular $\gamma$ grain within the expected crack path. In Fig. 5(d), a sketch of the reconstructed crack path and an SEM image of the fractured surface are depicted. Based on CSM, the crack evolved with a steady propagation rate over the first $95 \mathrm{~nm}$. Here, only minor drops were detected in the force-displacement curve, which may be linked to the activation of dislocation movement or mechanical twinning processes within the $\gamma$-phase. Based on the in situ CSM experiment, the $J$-integral reached a maximum value of $162 \mathrm{~J} / \mathrm{m}^{2}$ prior to unstable crack propagation. This is in good accordance with the (II) _C1 value before translamellar unstable crack growth through a coarse $\gamma$ lamella. Here, with a conditional fracture toughness of 3.7 MPa $\sqrt{ } \mathrm{m}$ and a calculated $K_{\mathrm{q}, \mathrm{j}}$ of $5.6 \mathrm{MPa} \sqrt{ } \mathrm{m}$, enhanced values in contrast to (II)_C1 cantilevers could be determined. Thereafter, the specimen failed by concurrent crack growth through the globular $\gamma$ grain and coarse $\gamma$ lamella. The deflection of the crack path along a presumed $\{111\}$ splitting plane within the globular $\gamma$ grain may be responsible for the enhanced fracture properties compared to the (II)_C1 specimen $[28,36,49,50]$. Therefore, the presence of globular $\gamma$ grains within $\alpha_{2} / \gamma$ colonies may be considered as beneficial for the case of improved fracture toughness. Furthermore, the crack front within the coarse $\gamma$ lamella reached a subjacent $\gamma / \gamma$ interface, which is highlighted by a white arrow in (d). During the experiment, no evident plastic zone evolved at the bottom side of the cantilever.

In the case of type (L) specimens, the notch was introduced perpendicular to the lamellar interfaces and, therefore, in general exhibits translamellar crack propagation. Furthermore, the absence of the $\alpha_{2}$-phase within the tested cantilevers could be determined by SEM investigations and leads to relatively ductile behavior.

As visible in Fig. 4, determined force-displacement curves of (L)_C1 and (L)_C2 specimens are almost identical in the first section. Therefore, both of the tested cantilevers are regarded as identical. Here, a constant slope and constant crack elongation could be determined until position (1) in Fig. 8. In the following, force-displacement curves of 


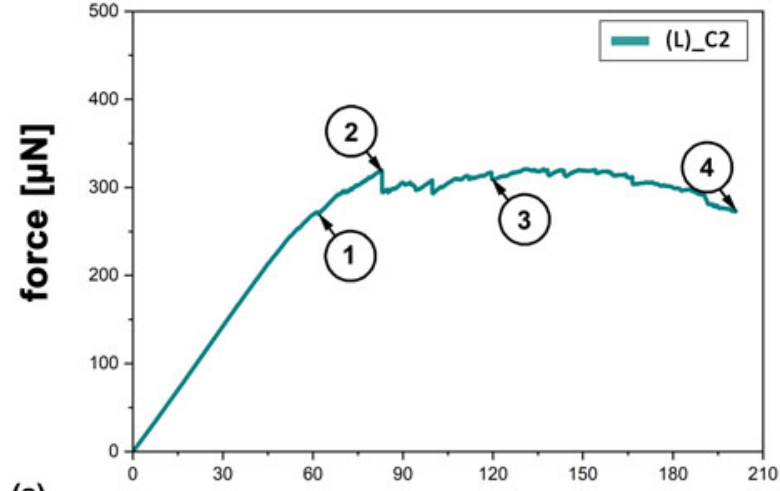

(a)

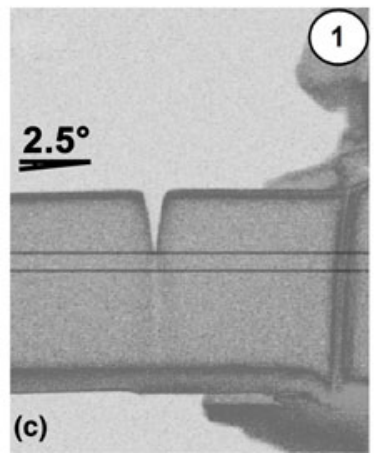

time [s]

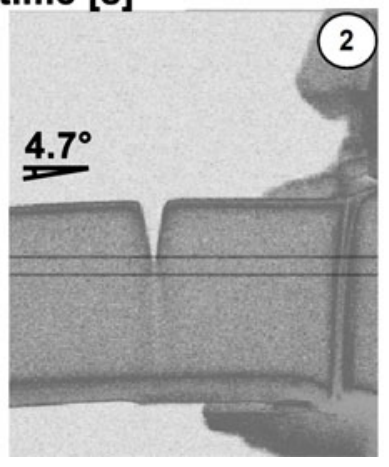

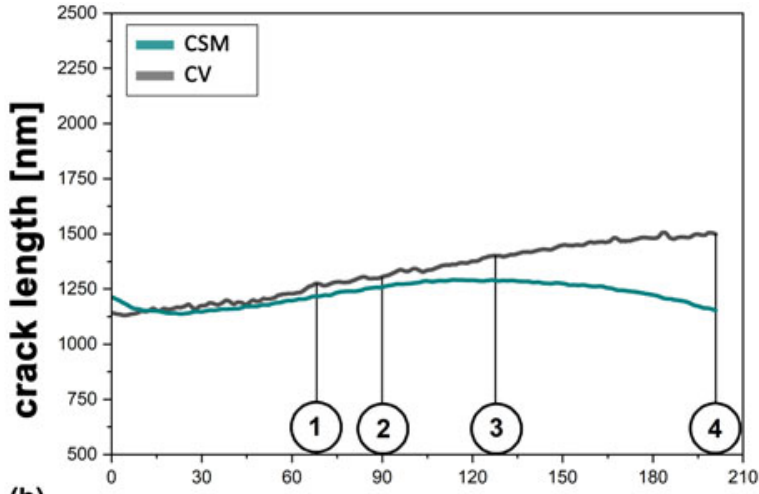

(b)

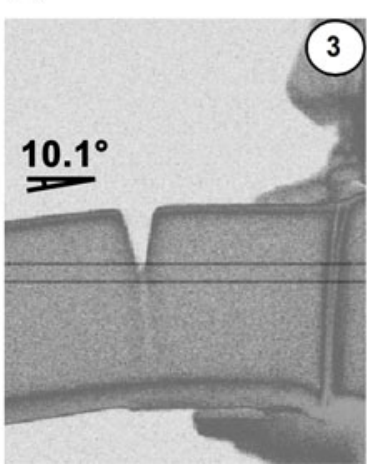

time [s]

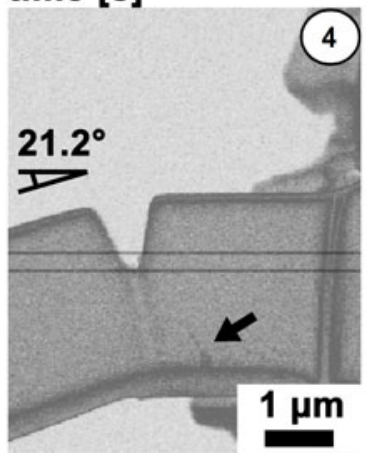

Figure 8: (a) Force-time data and (b) smoothed crack length-time data, determined by CSM and CV, of the (L)_C2 cantilever are displayed. Further, positions from 1-4 are marked in (a) and (b) corresponding to detailed images in (c). These micrographs are side-view snapshots of the in-situ SEM video and contain two horizontal lines to indicate crack growth during the experiment. Furthermore, the displayed bending angle indicates the deviation from the initial orientation of the cantilever in the advance of the experiment. In (c) (4), a black arrow denotes the presence of a band-like structure, visible on the cantilever's surface. Within the supplementary material (Supplementary Fig. S2), an SE SEM image displays the band-like structure in higher resolution and magnification.

specimens (L)_C1 and (L)_C2 both contain minor force drops including a distinct increase of displacement (see black arrows in Fig. 4). Hence, the sudden activation of glide systems within the $\gamma$-phase with emerging twins or dislocation movements are presumed [43].

The translamellar crack propagation is sketched in Fig. 6(a), including SEM images of the fractured surface shown in Fig. 6(b) and a side view of the tested (L)_C1 cantilever in Fig. 6(c). The ragged surface indicates severe plastic deformation during crack propagation. Furthermore, no distinct cleavage plane is visible and the crack was stopped at a $\gamma / \gamma$ interface [Fig. 6(c)].

Furthermore, $K_{\mathrm{q}}$ was determined after Eq. (2) at a designated force of $275.5 \mu \mathrm{N}$ for (L)_C1 and $319.5 \mu \mathrm{N}$ for (L)_C2 specimen, which leads to conditional fracture toughnesses of 3.3 and 3.7 $\mathrm{MPa} \sqrt{ } \mathrm{m}$, respectively. Since the cantilevers were positioned at an equal lateral height within the hosting $\alpha_{2} / \gamma$ colony, similar $\gamma$ lamellae were targeted during testing. Hence, the results of (L)_C1 and (L)_C2 cantilevers can be considered as equivalent. However, lower $K_{\mathrm{q}}$ values were determined due to the loss of strength of a $\gamma / \gamma$ arrangement in contrast to an $\alpha_{2} / \gamma$ composite [6]. Therefore, the absence of $\alpha_{2} / \gamma$ interfaces enables ductility and higher deformation durability without or at least only with minor crack propagation compared to type (II) specimens $[17,51]$. However, a similar mean $J$-integral value of $180 \pm 11 \mathrm{~J} / \mathrm{m}^{2}$ for translamellar crack propagation through a $\gamma$ lamella as in the case of the (II)_C1 cantilever was determined.

\section{Computer vision evaluation}

In Fig. 7, the calculated crack length after CSM is compared with the crack length determined by the $\mathrm{CV}$ method from the in situ SEM video of (II)_C2 cantilever, constituting a representative for type (II) specimen. For better visibility, both crack length data sets were smoothed applying a Lowess filter [52]. Here, different positions in Figs. 7(a) and 7(b) are marked to indicate stable crack growth (1), the maximum of stress intensity prior to unstable crack growth (2), the first data point after crack arrest (3), and the end of the experiment (4), respectively. The crack length data, evaluated by the CSM method, decreased to an initial value of about $866 \mathrm{~nm}$ and further indicates stable crack growth with increasing displacement. This behavior is attributed to the initial contact stiffness at the onset of the experiment, due to the contact effects of the indenter [41]. During stable crack growth, the determined crack lengths are almost coincident between the 
two methods. The onset of unstable crack growth was first detected by the CSM method, which is reasoned by the limited scan speed of the SEM with 6 frames/s. The evaluated crack propagation during the unstable crack event marked in Fig. 7 (b) by (2/3) amounts to 713 and $822 \mathrm{~nm}$ for the CSM and CV methods, respectively. Corresponding side-view SEM images in the SE mode are displayed in Fig. 7(c). However, a notable deviation of $441 \mathrm{~nm}$ between these methods in position (4) is visible. This behavior can be explained, on the one hand, by the formation of a distinct deformation zone at the bottom side of the cantilever and, therefore, in an increased effective cross-section. On the other hand, the CV method is merely able to track the crack path in one dimension. The fractured surface in Fig. 5(b) indicates an inconsistent crack growth along its cross-section. Here, the crack propagates further on the left-hand side of the fractured surface, featuring the visible part during in situ testing. Therefore, a combination of these effects is considered as responsible for the deviation. However, data analysis regarding toughness values and $J$-integral were only performed prior to first detected unstable crack growth and are, therefore, unaffected by this phenomenon occurring at large deflections and crack extensions.

Also, for type (L) cantilevers, the crack length was determined by the CSM and CV methods, respectively. The corresponding force- and crack length-time data for the (L)_C2 cantilever are displayed in Figs. 8(a) and 8(b). Numbers from 1 to 4 indicate the respective positions of SEM micrographs recorded during in situ experiments [Fig. 7(c)]. The $a_{n}$ calculated by CSM includes an initial contact phenomenon during the first seconds of the experiment. However, an average deviation of $48 \pm 6 \mathrm{~nm}$ is determined between the different methods until position (2). Therefore, a significant force drop evident in (a) (2) is accompanied by no measurable crack propagation in (b) (2), indicating mechanical twinning or dislocation slip events on an activated [111] plane within the prevailing $\gamma$ lamella $[21,31,34,50,53]$. The result of severe dislocation activity is visible as a band-like structure in (c) (4) and highlighted by an arrow. Furthermore, an increasing deviation in determined crack lengths from position (3) is noted. This deviation increases with the emerging blunting of the crack tip and increasing bending angle. A decreasing crack length as determined by the CSM method would indicate an apparent increase in stiffness during the experiment. Under the consideration that the Young's modulus remains constant, geometric changes of the cantilever must be taken into account to explain this. Furthermore, a minor slip of the wedge-shaped indenter away from the notch was noticed during the experiment. However, according to Eq. (1), this would lead to a decrease of $k_{n}$. Therefore, the effective cross-section of the cantilever is increased due to a combined effect of crack-tip blunting and the formation of a plastic zone at the bottom side of the cantilever [54]. This behavior becomes noticeable for bending angles above $7.1^{\circ}$ or a displacement of $2.23 \mu \mathrm{m}$ and, therefore, does not affect the results of Table 2. Apart from this, an increasing angle results in a change of the alignment of the wedge and the tested cantilever. This may influence the contact stiffness between the indenter and the specimen, thus resulting in a deviation of the calculated crack length at higher load-line displacements. Furthermore, a minor deviation of the crack from the ideal notch plane was determined at the positions 3 and 4 , which may also contribute to the observed discrepancy.

\section{Young's modulus}

Since the elastic properties are crucial in analyzing the data, an additional unnotched cantilever featuring similar dimensions as specimen (II)_C4 was fabricated to validate calculated stiffness values and to verify the calculated Young's modulus for type (II) specimens. This cantilever also exhibited a negative deviation angle $\varphi$ of $-7.7^{\circ}$ between lamellar orientation and presumed crack propagation direction due to the cantilever arrangement during fabrication. Furthermore, the distance between the base and the indenter $(11.39 \mu \mathrm{m})$ was kept constant compared to (II)_C4 specimen. Furthermore, the initial stiffness of this unnotched cantilever $\left(k_{0}\right)$ was determined from the corrected compliance. This compliance was augmented by subtracting the smoothed base compliance, consisting of the contact and machine compliance, which was determined at the base of the tested cantilever. The $k_{0}$ value could then be determined to be $1548 \mathrm{~N} / \mathrm{m}$ in the case of the (II)_C5 cantilever. Using Eq. (1), a Young's modulus of $186.8 \mathrm{GPa}$ for the specimen (II)_C5 was determined, which is in excellent accordance with the modulus of $189 \mathrm{GPa}$ calculated after the Reuss model (see the "Data evaluation and analysis" section). At this point, it should be noted that the determination of the Young's modulus is quite sensitive to minimal errors of the used parameters. Especially, caution in the determination of the dimensions $\mathrm{B}, \mathrm{W}$, and $\mathrm{L}$ is required. Therefore, a high standard deviation of the determined Young's modulus is expected.

\section{Discussion}

In general, type (II) specimens exhibit very similar force-displacement curves, containing an initial elastic part denoted by a constant slope. Furthermore, a matching stable crack elongation could be determined by CSM and CV. This is accompanied by minor but sudden drops visible within the forcedisplacement data of Fig. 3(a) (black arrows). These drops indicate the formation of twins or the activation of discrete dislocation glide events within $\gamma$ lamellae on specific $\{111\}$ planes $[27,53]$. Based on acoustic emission experiments, the 
development of mechanical twins within the $\gamma$ phase is activated earlier and more pronounced as dislocation induced deformation $[55,56]$. The formation of twins is furthermore considered as a major deformation mechanism in micromechanical specimens and within the plastic zone in front of the crack tip [17, 30, 31, 43]. Hence, the role of ordinary dislocations increases with increasing deformation [56].

The measured conditional fracture toughnesses from type (II) specimens are in good agreement with results from polysynthetically twinned TiAl alloys exhibiting a similar lamellar orientation, where maximum values of 3.6 or $3.4 \mathrm{MPa} \sqrt{ } \mathrm{m}$ were observed [6, 43]. Halford et al. [18] determined a mean $K_{\mathrm{q}}$ value of $3.7 \mathrm{MPa} \sqrt{ } \mathrm{m}$ for interlamellar fracture mode regarding the so-called TiAl-Alloy 7. Consequently, higher values could be measured by increasing the translamellar ratio of the fractured surface [18].

The elevated $K_{\mathrm{q}}$ and $J$-integral values (Table 2) along $\alpha_{2} / \gamma$ interfaces from type (II) specimen are in agreement with the computational results of the work of separation energies for different $\gamma$ interface types and $\alpha_{2} / \gamma$ interface within a binary TiAl alloy [36, 57]. Kanani et al. [57] proposed that the separation energies of an $\alpha_{2} / \gamma$ interface exceed those of different $\gamma$ interface types. According to Yoo and $\mathrm{Fu}$ [51], the cleavage energy of different $\gamma / \gamma$ interfaces ranges between 4.2 and $4.4 \mathrm{~J} / \mathrm{m}^{2}$, whereas it amounts to $4.5 \mathrm{~J} / \mathrm{m}^{2}$ for $\alpha_{2} / \gamma$ interfaces. An increased concentration of interstitials leads to a reduction of the cleavage energy of the $\alpha_{2} / \gamma$ interfaces to $3.8 \mathrm{~J} / \mathrm{m}^{2}$.

The determined $K_{\mathrm{q}}$ values of type (II) specimens behave similarly, except specimen (II)_C1, where a distinct plastic zone is formed at the bottom side of the cantilever. Furthermore, the presence of 0.3 at.\% of $\mathrm{C}$ in the $\mathrm{TNM}^{+}$ alloy leads to an increased hardness of the $\alpha_{2}$ and $\gamma$-phase and is predominantly enriched within $\alpha_{2}$ lamellae $[45,58]$. The results of this study confirm a higher fracture strength of $\alpha_{2} / \gamma$ interfaces despite the assumed embrittling effect of $\mathrm{C}$ within $\alpha_{2}$ lamellae [58]. This is evoked by the higher solubility of $\mathrm{C}$ and $\mathrm{Si}$ within the $\alpha_{2}$-phase compared to the $\gamma$-phase. Therefore, compared to polysynthetically twinned $\gamma$-TiAl, slightly higher $K_{\mathrm{q}}$ values are achieved for the $\mathrm{TNM}^{+}$alloy. The stabilization annealing step of the heat treatment at $900{ }^{\circ} \mathrm{C}$ for $3 \mathrm{~h}$ leads to a decreasing mean width of $\alpha_{2}$ lamellae and concomitant precipitation of $\zeta-\mathrm{Ti}_{5} \mathrm{Si}_{3}$ silicides along with repeating $\alpha_{2} / \gamma$ interfaces $[9,59,60,61]$. Karadge et al. [60] proposed the movement of $\mathrm{C}$ from $\alpha_{2} / \gamma$ interfaces into the center of $\alpha_{2}$ lamellae based on energy-filtered transmission electron microscope (TEM) investigations. This is reasoned by the increasing size of octahedral sites by decreasing misfit strains along the $\alpha_{2} / \gamma$ interface to the center of the adjoining $\alpha_{2}$ lamellae $[49,60,62]$. In contrast to this, $S i$ is enriched along $\alpha_{2} / \gamma$ interfaces and if the solubility level is reached, $\zeta-\mathrm{Ti}_{5} \mathrm{Si}_{3}$ silicides are precipitated $[9,59]$. Therefore, during testing, failure along $\gamma / \gamma$ interfaces and translamellar $\alpha_{2}$ fracture is preferred. This may be explained by the assumed strengthening effect of persistent $\zeta-\mathrm{Ti}_{5} \mathrm{Si}_{3}$ silicides, enabling to compensate the embrittling effect of $C$ within $\alpha_{2} / \gamma$ colonies. However, the strengthening effect of $\zeta-\mathrm{Ti}_{5} \mathrm{Si}_{3}$ silicides located along the $\alpha_{2} / \gamma$ interface could not be precisely quantified. Nevertheless, the crack was deflected from its intended path, which indicates a distinct toughening effect for an increasing number of particles [63]. Though, due to different $\zeta-\mathrm{Ti}_{5} \mathrm{Si}_{3}$ morphologies and interface types, the strengthening effect could not be confirmed doubtlessly [47].

Concluding, fracture parameters, crack propagation, and force-displacement data of type (II) specimens confirm a semibrittle interlamellar fracture behavior along $\gamma / \gamma$ and $\alpha_{2} / \gamma$ interfaces [64].

In the case of type $(\mathrm{L})$ specimen, lower $K_{\mathrm{q}}$ values were determined due to the loss of strength of a $\gamma / \gamma$ laminate in contrast to an $\alpha_{2} / \gamma$ arrangement [6]. Calculated $K_{\mathrm{q}, \mathrm{j}}$ values and elevated $J_{\mathrm{pl}}$ fractions compared to $J_{\mathrm{el}}$ values indicate a major influence of plastic deformation during the experiments. According to Appel and Wagner [50], deformation of the $\gamma$-phase primarily takes place on $\{111\}$ planes by ordinary dislocations and mechanical twinning. When the crack follows $\{111\}_{\gamma}$ planes, it is deflected at $\gamma / \gamma$ interfaces due to the crystallographic orientation change of the $\gamma$ lamellae. In front of the crack tip, the formation of deformation twins within the several micron-sized plastic zone was reported [17, 43, 50]. During the in situ testing of the (L)_C2 cantilever, a band-like structure evolved on the surface and is visible in Fig. 8(c) [21, 27]. This indicates twinning or high dislocation mobility and, therefore, distinct ductile behavior of this specimen condition. Ding et al. determined the importance of mechanical twinning within a polysynthetically twinned TiAl alloy and identified the formation of twins in front of the crack tip as the main reason for crack growth [43].

Regarding the results of CSM and CV measurements, the determined crack lengths are in good accordance until the cleavage of the $\alpha_{2} / \gamma$ interface of (II)_C2 specimen. The measured deviation between both data sets in position (3) of Fig. 7(b) was determined to be $145 \mathrm{~nm}$. Considering the inconsistent fractured surface in Fig. 5(b), a reduced mean crack propagation of $167 \mathrm{~nm}$ as indicated by CV was observed. Besides this, the already mentioned geometric changes during testing may explain the deviation in position (4).

Furthermore, the determined crack lengths from CSM and CV measurements of (L)_C2 specimen are in good accordance up to a displacement of $2.23 \mu \mathrm{m}$, which is located between position (2) and (3) in Fig. 8. Due to the formation of a plastic zone accompanied by the appearance of a glide step on the surface of the cantilever and the blunting of the crack tip a geometric change of the cantilever ensues. Furthermore, a 
deviation of contact stiffness originating from the geometric details of the used indenter tip, due to the changing contact angle must be taken into account. However, considering a straight crack front, the complementary CV method enables to access valid crack lengths during the entire experiment. Thus, the translamellar crack propagation was determined to be constant during the loading part of the experiment. The force-displacement data and the observation of a band-like structure indicate a distinct ductile behavior of the investigated material during translamellar fracture experiments [64].

These findings are in contrast to macroscopic tests on the investigated alloy, where a rather brittle behavior is reported [5]. To enhance the fracture toughness of the entire $\alpha_{2} / \gamma$ colony, strengthening of the weakest interface type is required. Furthermore, the number of $\alpha_{2} / \gamma$ interfaces can be increased by a sufficient heat treatment to decrease the lamellar spacing. The amount of $\alpha_{2}$ phase and $\zeta-\mathrm{Ti}_{5} \mathrm{Si}_{3}$ silicides may be optimized by the alloying concept in order to enlarge the number of strengthened $\alpha_{2} / \gamma$ interfaces. However, macroscopically thinner lamellae within the $\alpha_{2} / \gamma$ colonies would result in a strain localization along the colony boundaries and thus higher tendency for crack initiation [32,39]. Also, a change in the $\alpha_{2} / \gamma$ ratio and significantly lower lamellar spacing are reported to affect coherency [19,62]. Furthermore, the presence of small globular $\gamma$ grains along different interfaces may improve fracture behavior. To obtain balanced mechanical properties and optimized fracture behavior, all contributing length scales must be considered and evaluated as reported in Refs. [11, 12, 53].

The minimal size of the calculated plastic zone exceeds the dimensions of the fabricated cantilevers by far [65]. Therefore, the fracture toughness according to ASTM E399 is not size-independent and thus shown values are of conditional nature.

\section{Conclusions}

Within this study, micro-sized cantilevers with a parallel or perpendicular orientation of $\alpha_{2} / \gamma$ lamellae to the expected crack propagation plane (type (II) or (L)) were successfully fabricated from a fully lamellar intermetallic $\mathrm{TNM}^{+}$alloy. These cantilevers were tested at RT in situ with simultaneous CSM during loading and supplementary recording of in situ SEM videos. This allows the determination of crack propagation based on continuous stiffness and CV methods for both specimen types. $K_{\mathrm{q}}$, J-integral, and the resulting $K_{\mathrm{q}, j}$ were calculated and compared with data from the existing literature allowing the following conclusions to be drawn:

(i) Based on the force-displacement data, the formation of glide steps and the existence of a distinct plastic zone at the bottom side of certain cantilevers, a semi-brittle to ductile fracture behavior of the investigated $\mathrm{TNM}^{+}$alloy is assumed to prevail in micro-scale.

(ii) $K_{\mathrm{q}}$ values range, in case of type (II) cantilevers, between 3.2 and $4.4 \mathrm{MPa} \sqrt{ } \mathrm{m}$ for $\gamma / \gamma$ and $\alpha_{2} / \gamma$ interfaces, respectively. Type (L) cantilevers reached 3.3 and 3.7 $\mathrm{MPa} \sqrt{ } \mathrm{m}$ due to significant lower attained force levels, based on the lack of $\alpha_{2}$ lamellae in the tested volumes.

(iii) Furthermore, the highest $J$-integral value of $553 \mathrm{~J} / \mathrm{m}^{2}$ was determined for a $\gamma / \gamma$ interface in the case of a type (II) cantilever. This was substantiated in the good deformability of a rather broad $\gamma$ lamella, exhibiting an adequate number of available glide or twin planes next to the crack tip.

(iv) Bridging of $\alpha_{2}$ and $\gamma$ ligaments, crack deflection due to globular $\gamma$ grains along $\gamma / \gamma$ interfaces and an assumed strengthening effect based on the presence of $\zeta-\mathrm{Ti}_{5} \mathrm{Si}_{3}$ silicides along $\alpha_{2} / \gamma$ interfaces could be identified for type (II) cantilevers.

(v) Due to the lack of $\alpha_{2}$ lamella and the presence of numerous available slip systems within the $\gamma$-phase, gradually blunting of the crack tip and a ductile material behavior was determined for type (L) cantilevers. Furthermore, during in situ experiments, they exhibit a steady crack propagation without pronounced unstable events.

(vi) In situ crack length determination by CSM and an ex situ evaluation of the recorded video signal by $\mathrm{CV}$ was implemented for selected specimens. While both generally agree well upon force drops or severe crack propagation events, a distinct deviation in determined crack lengths was observed for type (L) cantilevers at large bending deflections.

Concluding, fundamental knowledge concerning fracture behavior of different interface types of an advanced 4th generation TiAl alloy was gathered. Hence, the understanding of critical material parameters and, thus, the basis for improvements regarding crack propagation in fully lamellar microstructures is provided.

\section{Methodology}

\section{Material}

The material investigated in this study is based on the TNM alloying concept improved by nominal additions of 0.3 at.\% $\mathrm{C}$ and 0.3 at.\% Si. The actual chemical composition is $\mathrm{Ti}-$ $43.3 \mathrm{Al}-4.02 \mathrm{Nb}-0.96 \mathrm{Mo}-0.12 \mathrm{~B}-0.34 \mathrm{C}-0.31 \mathrm{Si}$ (in at.\%) and is denominated as $\mathrm{TNM}^{+}$alloy $[2,9,10]$. It was processed by plasma arc melting (PAM) and supplied by Hanseatische Waren Handelsgesellschaft mbH \& Co KG, Bremen, Germany. After casting, the material was subjected to a hot isostatic 
pressing (HIP) procedure at $1200{ }^{\circ} \mathrm{C}$ and $200 \mathrm{MPa}$ for $4 \mathrm{~h}$ to homogenize the microstructure and reduce residual casting porosity. The material's microstructure investigated in the present study was adjusted in atmospheric condition in a hightemperature furnace Carbolite RHF 1600 equipped with three type-S thermocouples. The heat treatment according to Klein et al. [9], enabling the precipitation of $\gamma$ lamellae within the supersaturated $\alpha_{2}$ grains, leads to the formation of $\alpha_{2} / \gamma$ colonies, which represent the FL microstructure subjected to the detailed analyses reported here. The resultant mean lamellar spacing was $248 \mathrm{~nm}$, including a standard deviation of $150 \mathrm{~nm}$ [10]. This was determined by conventional TEM using a Philips CM 12 microscope in the edge-on condition of the $\mathrm{TNM}^{+}$specimen [66]. Two different $\alpha_{2} / \gamma$ colonies with no preferred orientation are found in Supplementary Fig. S1.

\section{Experimental setup and specimens}

The tested cantilevers were fabricated by focused ion beam (FIB) milling with subsequently decreasing currents from $5 \mathrm{nA}$ for coarse cuts down to $20 \mathrm{pA}$ for final polishing and notch cutting. The aforementioned FIB column is operated within a scanning electron microscope (SEM/FIB; Zeiss Auriga Laser platform, Carl Zeiss AG, Oberkochen, Germany). Their final dimensions, position, notch depth, and orientation of the $\alpha_{2} / \gamma$ lamellae were determined from micrographs recorded by the use of SE and BSE detectors attached to the SEM/FIB workstation. All measurements were conducted manually using ImageJ v1.5.3. The symbol (L) in the designation indicates a perpendicular and the symbol (II) a parallel alignment of the $\alpha_{2} / \gamma$ lamellae to the notch and, therefore, to the presumed crack propagation direction. This should lead in the case of type (II) and (L) cantilever to an interlamellar and translamellar crack growth, respectively. However, a minor deviation to the requested orientation was determined by SEM and is denoted as angle $\varphi$ in Table 1 . The fracture tests were conducted in situ in an SEM (LEO 1540XB, Carl Zeiss AG, Oberkochen, Germany) using a Hysitron pico-indenter PI-85 (Bruker Corporation, Billerica, USA) equipped with a $60^{\circ}$ wedge-shaped conductive diamond tip (Synton-MDP, Nidau, Switzerland) and a CSM module. During testing, a loading rate of $10 \mu \mathrm{N} / \mathrm{s}$ and a maximum displacement of $5 \mu \mathrm{m}$ was used.

\section{Data evaluation and analysis}

The aforementioned experimental setup allows to constantly record the compliance and therefore to continuously evaluate the stiffness of the cantilevers [41]. The measured forcedisplacement and dynamic stiffness data were acquired at a rate of 300 points/s and the respective corresponding in situ images were captured at a rate of 6 frames/s. The initial stiffness of the unnotched cantilever $k_{0}$ is calculated by classical Euler-Bernoulli beam theory according to Eq. (1):

$$
k_{0}=\frac{E \cdot B \cdot W^{3}}{4 \cdot L^{3}}
$$

where $E$ denotes the Young's modulus of $\gamma$-TiAl with $189 \mathrm{GPa}$ for type (L) cantilevers at RT, which was calculated after the Reuss model for layered composites according to the moduli of the $\alpha_{2}$ - and $\gamma$-phase with 160 and $200 \mathrm{GPa}$, respectively [46]. Furthermore, $L, B$, and $W$ represent the bending length, width, and height of the cantilever. An SE image of a cantilever including its geometrical dimensions is illustrated in Fig. 1(b). The dynamic stiffness $k_{n}$ for the actual data point $n$ was evaluated by the inverse of dynamic compliance and is assessed by the continuous compliance measurement during the experiment. Subsequently, the actual crack length $\left(a_{n}\right)$ was calculated after an analytical approach following Alfreider et al. [40].

Following ASTM E399, linear elastic fracture mechanics (LEFM) requires a minimum dimension of the initial crack length $\left(a_{\mathrm{c}}\right)$ and $B$ concerning the magnitude of the plastic zone, which is defined as $2.5 \cdot K_{\mathrm{IC}}^{2} / \sigma_{y}^{2}[65,67]$. Here, $K_{\mathrm{IC}}$ and $\sigma_{y}$ represent the material's fracture toughness and the yield strength, respectively. This would result in a required $a_{\mathrm{c}}$ and $B$ values of $10 \mu \mathrm{m}$ and a resulting minimum $L$ of $129 \mu \mathrm{m}$. This specimen size would exceed the mean $\alpha_{2} / \gamma$-colony size within the microstructure of the investigated $\mathrm{TNM}^{+}$alloy and necessitates smaller dimensions of the fabricated cantilevers (Table 1) $[5,6]$. Therefore, LEFM is not valid, the conditional stress intensity factor $\left(K_{\mathrm{q}, n}\right)$ for the actual data point $n$ is calculated using the following equation according to ASTM 399 [65]:

$$
K_{\mathrm{q}, n}=\frac{F_{n} \cdot L_{\mathrm{c}}}{B \cdot W^{1.5}} \cdot f\left(\frac{a_{n}}{W}\right)
$$

where $F_{n}$ denotes the actual load, $L_{\mathrm{c}}$ the cantilever's length to the notch, and $f\left(a_{n} / W\right)$ denotes the geometry factor after Wurster et al. [67]. Furthermore, taking into account the plastic part, the J-integral based on elastic-plastic fracture mechanics is calculated using the iterative method according to ASTM $1820[68,69,70]$. The $J$-integral for actual data point $\left(J_{n}\right)$ is derived from the sum of elastic $J_{n}^{\mathrm{el}}$ and plastic $J_{n}^{\mathrm{pl}}$ parts following Eqs. (3)-(5).

$$
\begin{gathered}
J_{n}=J_{n}^{\mathrm{el}}+J_{n}^{\mathrm{pl}}, \\
J_{n}^{\mathrm{el}}=\frac{K_{\mathrm{q}, n}^{2}\left(1-v^{2}\right)}{E},
\end{gathered}
$$




$$
\begin{aligned}
J_{n}^{\mathrm{pl}}= & \left(J_{n-1}^{\mathrm{pl}}+\frac{\eta}{W-a_{n}} \cdot \frac{A_{n}^{\mathrm{pl}}-A_{n-1}^{\mathrm{pl}}}{B}\right) \\
& \cdot\left(1-\gamma^{\prime} \cdot \frac{a_{n}-a_{n-1}}{W-a_{n}}\right)
\end{aligned}
$$

According to Schafrik [71], the Poisson's ratio $v$ for a binary TiAl alloy at RT amounts to 0.233 . The plastic work at the actual data point $n$, entitled $A_{n}^{\mathrm{pl}}$, corresponds to the area below the load-displacement curve subtracted by the elastic work and is calculated by numeric integration [41, 69]. Here, occasional negative $A_{n}^{\mathrm{pl}}$ values due to noise in the measured data are set to zero and are, therefore, not regarded as valid data points in the calculation of $J_{n}^{\mathrm{pl}}$. The constants $\eta$ and $\gamma^{\prime}$ possess values of 1.9 and 0.9 , respectively [41].

To compare $K_{\mathrm{q}}$ values from LEFM with calculated $J$-integral values, Eq. (6) is used $[67,72]$ :

$$
K_{\mathrm{q}, j}=\sqrt{\frac{J_{\mathrm{q}} \cdot E}{1-v^{2}}} .
$$

After in situ testing, the microcantilevers were bent to an angle of at least $45^{\circ}$ to enable analysis of the fracture surface using SEM.

Besides the CSM-based approach, the crack propagation during the experiments was further analyzed by $\mathrm{CV}$ methods on the visible specimen surface during the experiment [38, 42]. Therefore, the image is binarized and the crack flank is extracted without the necessity of surface speckle patterns $[21,34,42]$. The crack length is measured in the $x$ - and $y$-direction by assuming a fixed point at the sample top surface where the crack was initialized. To improve the accuracy of this method, drift correction was applied to eliminate influences due to thermal and mechanical shifting. Typically, an error of \pm 3 pixels, relating to crack-tip detection and recognition errors, arises. To enhance the quality of crack detection, different filters, e.g., non-local means and Gaussian are used. However, the determined crack length accuracy depends on magnification, signal-to-noise ratio and image resolution, as well as the image acquisition rate.

\section{Acknowledgments}

The authors acknowledge funding by the European Research Council under Grant number: 771146 (M.B., K.S., D.K.). Financial support by the Austrian Federal Government (837900) represented by Österreichische Forschungsförderungsgesellschaft $\mathrm{mbH}$ and the Styrian and the Tyrolean Provincial Government within the framework of the COMET Funding Programme (IC-MPPE, A1.24), as well as partial financial support by the Austrian Science Fund FWF (project number P25325-N20) is gratefully acknowledged (M.A.).

\section{Data availability}

The data sets generated during the current study are available from the corresponding author on a reasonable request.

\section{Supplementary material}

To view supplementary material for this article, please visit https://doi.org/10.1557/jmr.2020.306.

\section{References}

1. H. Clemens and S. Mayer: Intermetallic titanium aluminides in aerospace applications - Processing, microstructure and properties. Mater. High Temp. 33, 560 (2016).

2. S. Mayer, P. Erdely, F.D. Fischer, D. Holec, M. Kastenhuber, T. Klein, and H. Clemens: Intermetallic $\beta$-solidifying $\gamma$-TiAl based alloys - From fundamental research to application. Adv. Eng. Mater. 19, 1600735 (2017).

3. M. Masiol and R.M. Harrison: Aircraft engine exhaust emissions and other airport-related contributions to ambient air pollution: A review. Atmos. Environ. 95, 409 (2014).

4. B.P. Bewlay, S. Nag, A. Suzuki, and M.J. Weimer: TiAl alloys in commercial aircraft engines. Mater. High Temp. 33, 549 (2016).

5. D. Wimler, J. Lindemann, H. Clemens, and S. Mayer: Microstructural evolution and mechanical properties of an advanced $\gamma$-TiAl based alloy processed by spark plasma sintering. Materials 12, 1523 (2019).

6. D. Miyaguchi, M. Otsu, K. Takashima, and M. Takeyama: Microscale fracture toughness testing of TiAl PST crystals. MRS Proc. 1128-U05-14 (2008).

7. C.T. Liu, J.H. Schneibel, P.J. Maziasz, J.L. Wright, and D.S. Easton: Tensile properties and fracture toughness of TiAl alloys with controlled microstructures. Intermetallics 4, 429 (1996).

8. Q. Wang, H. Ding, H. Zhang, R. Chen, J. Guo, and H. Fu: Variations of microstructure and tensile property of $\gamma$-TiAl alloys with 0-0.5 at\% C additives. Mater. Sci. Eng. A 700, 198 (2017).

9. T. Klein, L. Usategui, B. Rashkova, M.L. Nó, J. San Juan, H. Clemens, and S. Mayer: Mechanical behavior and related microstructural aspects of a nano-lamellar TiAl alloy at elevated temperatures. Acta Mater. 128, 440 (2017).

10. M. Burtscher, T. Klein, S. Mayer, H. Clemens, and F.D. Fischer: The creep behavior of a fully lamellar $\gamma$-TiAl based alloy. Intermetallics 114, 106611 (2019).

11. M. Kastenhuber, T. Klein, H. Clemens, and S. Mayer: Tailoring microstructure and chemical composition of advanced $\gamma$-TiAl based alloys for improved creep resistance. Intermetallics $\mathbf{9 7}, 27$ (2018).

12. T. Leitner, M. Schloffer, S. Mayer, J. Eßlinger, H. Clemens, and R. Pippan: Fracture and R-curve behavior of an intermetallic 
$\beta$-stabilized TiAl alloy with different nearly lamellar microstructures. Intermetallics 53, 1 (2014).

13. M. Beschliesser, A. Chatterjee, A. Lorich, W. Knabl, H. Kestler, G. Dehm, and H. Clemens: Designed fully lamellar microstructures in a $\gamma$-TiAl based alloy: Adjustment and microstructural changes upon long-term isothermal exposure at 700 and $800^{\circ} \mathrm{C}$. Mater. Sci. Eng. A 329-331, 124 (2002).

14. J. Wang and T. Nieh: Creep of a beta phase-containing TiAl alloy. Intermetallics 8, 737 (2000).

15. E. Schwaighofer, H. Clemens, J. Lindemann, A. Stark, and S. Mayer: Hot-working behavior of an advanced intermetallic multi-phase $\gamma$-TiAl based alloy. Mater. Sci. Eng. A 614, 297 (2014).

16. S.J. Balsone, B.D. Worth, J.M. Larsen, and J.W. Jones: Fractographic study of fatigue crack growth processes in a fully lamellar $\gamma$-TiAl alloy. Scr. Metall. Mater. 32, 1653 (1995).

17. Z.W. Huang, P. Bowen, and I.P. Jones: Transmission electron microscopy investigation of fatigue crack tip plastic zones in a polycrystalline $\gamma$-TiAl-based alloy. Philos. Mag. A 81, 2183 (2001).

18. T.P. Halford, K.K. Takashima, Y. Higo, and P. Bowen: Fracture tests of microsized TiAl specimens. Fatigue Fract. Eng. Mater. Struct. 28, 695 (2005).

19. A. Chauniyal and R. Janisch: Influence of lattice misfit on the deformation behaviour of $\alpha_{2} / \gamma$ lamellae in TiAl alloys. Mater. Sci. Eng. A 796, 140053 (2020).

20. E. Bayraktar: On the giga cycle fatigue behaviour of two-phase $\left(\alpha_{2}+\gamma\right)$ TiAl alloy. Int. J. Fatigue 26, 1263 (2004).

21. T. Edwards: Recent progress in the high-cycle fatigue behaviour of $\gamma$-TiAl alloys. Mater. Sci. Technol. 34, 1919 (2018).

22. J. Arata, K.S. Kumar, W.A. Curtin, and A. Needleman: Crack growth in lamellar titanium aluminide. Int. J. Fract. 111, 163 (2001).

23. Y. Lu, Y. Zhang, L. Qiao, Y-B. Wang, C. Chen, and W. Chu: In-situ TEM study of fracture mechanisms of polysynthetically twinned (PST) crystals of TiAl alloys. Mater. Sci. Eng. A 289, 91 (2000).

24. B.D. Worth, J.M. Larsen, S.J. Balsone, and J.W. Jones: Mechanisms of ambient temperature fatigue crack growth in Ti-46.5Al-3Nb-2Cr-0.2W. Metall. Mater. Trans. A 28, 825 (1997).

25. K.S. Chan and Y-W. Kim: Effects of lamellae spacing and colony size on the fracture resistance of a fully-lamellar TiAl alloy. Acta Metall. Mater. 43, 439 (1995).

26. H. Clemens, M. Schloffer, E. Schwaighofer, R. Werner, A. Gaitzenauer, B. Rashkova, T. Schmoelzer, R. Pippan, and S. Mayer: Advanced $\beta$-solidifying titanium aluminides - development status and perspectives. MRS Proc. 1516, 3 (2013).

27. F. Iqbal, F. Pyczak, S. Neumeier, and M. Göken: Crack nucleation and elastic/plastic deformation of TiAl alloys investigated by in-situ loaded atomic force microscopy. Mater. Sci. Eng. A 689, 11 (2017).
28. F. Appel, U. Lorenz, U. Sparka, and R. Wagner: Effects of dislocation dynamics and microstructure on crack growth mechanisms in two-phase titanium aluminide alloys. Intermetallics 6, 603 (1998).

29. I. Dlouhý, L. Stratil, H. Fukutomi, and M. Hasegawa: Crack resistance characterization in TiAl intermetallics with enhanced toughness. KEM 741, 13 (2017).

30. K.S. Chan: Understanding fracture toughness in gamma TiAl. JOM 44, 30 (1992).

31. A.J. Palomares-García, M.T. Pérez-Prado, and J.M. Molina-Aldareguia: Effect of lamellar orientation on the strength and operating deformation mechanisms of fully lamellar TiAl alloys determined by micropillar compression. Acta Mater. 123, 102 (2017).

32. T.E.J. Edwards, F. Di Gioacchino, and W.J. Clegg: An experimental study of the polycrystalline plasticity of lamellar titanium aluminide. Int. J. Plast. 118, 291 (2019).

33. R.O. Ritchie, J.H. Kinney, J.J. Kruzic, and R.K. Nalla: A fracture mechanics and mechanistic approach to the failure of cortical bone. Fatigue Fract. Eng. Mater. Struct. 28, 345 (2005).

34. A.J. Palomares-García, M.T. Pérez-Prado, and J.M. Molina-Aldareguia: Slip transfer across $\gamma$-TiAl lamellae in tension. Mater. Des. 146, 81 (2018).

35. G. Hénaff, B. Bittar, C. Mabru, J. Petit, and P. Bowen: Fatigue crack propagation resistance of a $\mathrm{Ti}_{48} \mathrm{Al}_{2} \mathrm{Mn}_{2} \mathrm{Nb}$ alloy in the as-cast condition. Mater. Sci. Eng. A 219, 212 (1996).

36. A. Neogi, M. Alam, A. Hartmaier, and R. Janisch: Anisotropic failure behavior of ordered intermetallic TiAl alloys under pure mode-I loading. Model. Simul. Mater. Sci. Eng. 28, 65016 (2020).

37. K.S. Chan and Y-W. Kim: Relationships of slip morphology, microcracking, and fracture resistance in a lamellar TiAl-alloy. Metall. Mater. Trans. A 25, 1217 (1994).

38. T.E.J. Edwards, F. Di Gioacchino, A.J. Goodfellow, and W.J. Clegg: Slip bands in lamellar TiAl during high cycle fatigue microcompression by correlative total strain mapping, diffraction orientation mapping and transmission electron imaging. Int. J. Fatigue 124, 520 (2019).

39. J.E. Schnabel and S. Bargmann: Accessing colony boundary strengthening of fully lamellar TiAl alloys via micromechanical modeling. Materials 10, 869 (2017).

40. M. Alfreider, S. Kolitsch, S. Wurster, and D. Kiener: An analytical solution for the correct determination of crack lengths via cantilever stiffness. Mater. Des., 194, 108914 (2020).

41. M. Alfreider, D. Kozic, O. Kolednik, and D. Kiener: In-situ elastic-plastic fracture mechanics on the microscale by means of continuous dynamical testing. Mater. Des. 148, 177 (2018).

42. T.E.J. Edwards, F. Di Gioacchino, and W.J. Clegg: High resolution digital image correlation mapping of strain localization upon 
room and high temperature, high cycle fatigue of a TiAl intermetallic alloy. Int. J. Fatigue 142, 105905 (2021).

43. R. Ding, Y. Chiu, M. Chu, S. Paddea, and G. Su: A study of fracture behaviour of gamma lamella using the notched TiAl micro-cantilever. Philos. Mag. 100, 982 (2020).

44. K. Tanaka: Single-crystal elastic constants of gamma-TiAl. Philos. Mag. Lett. 73, 71 (1996).

45. T. Klein, B. Rashkova, D. Holec, H. Clemens, and S. Mayer: Silicon distribution and silicide precipitation during annealing in an advanced multi-phase $\gamma$-TiAl based alloy. Acta Mater. 110, 236 (2016).

46. M. Göken, M. Kempf, and W.D. Nix: Hardness and modulus of the lamellar microstructure in PST-TiAl studied by nanoindentations and AFM. Acta Mater. 49, 903 (2001).

47. F-S. Sun, S-E. Kim, C-X. Cao, Y-T. Lee, and M-G. Yan: A study of $\mathrm{Ti}_{5} \mathrm{Si}_{3} / \gamma$ interface in TiAl alloys. Scr. Mater. 45, 383 (2001).

48. J.L. Heatherly, E.P. George, C.T. Liu, and M. Yamaguchi: A study of the cleavage fracture behavior of PST TiAl alloys. Mater. Sci. Eng. A 239-240, 404 (1997).

49. F. Appel and U. Christoph: Coherency stresses and interface-related deformation phenomena in two-phase titanium aluminides. Intermetallics 7, 1173 (1999).

50. F. Appel and R. Wagner: Microstructure and deformation of two-phase $\gamma$-titanium aluminides. Mater. Sci. Eng. R 22, 187 (1998).

51. M.H. Yoo and C.L. Fu: Physical constants, deformation twinning, and microcracking of titanium aluminides. Metall. Mat. Trans. A 29, 49 (1998).

52. W.S. Cleveland: Robust Locally Weighted Regression and Smoothing Scatterplots. J. Am. Stat. Assoc. 74, 829 (1979).

53. F. Appel, J. Paul, and M. Oehring: Gamma Titanium Aluminide Alloys: Science and Technology (Wiley-VCH, Weinheim, 2011).

54. Y. Du, J. Shen, Y. Xiong, Z. Shang, L. Wang, and H. Fu: Lamellar microstructure alignment and fracture toughness in $\mathrm{Ti}-47 \mathrm{Al}$ alloy by electromagnetic confinement and directional solidification. Mater. Sci. Eng. A 621, 94 (2015).

55. F. Kauffmann, T. Bidlingmaier, G. Dehm, A. Wanner, and

H. Clemens: On the origin of acoustic emission during room temperature compressive deformation of a $\gamma$-TiAl based alloy. Intermetallics 8, 823 (2000).

56. W.T. Marketz, F.D. Fischer, F. Kauffmann, G. Dehm, T. Bidlingmaier, A. Wanner, and H. Clemens: On the role of twinning during room temperature deformation of $\gamma$-TiAl based alloys. Mater. Sci. Eng. A 329-331, 177 (2002).

57. M. Kanani, A. Hartmaier, and R. Janisch: Interface properties in lamellar TiAl microstructures from density functional theory. Intermetallics 54, 154 (2014).

58. T. Klein, M. Schachermayer, F. Mendez-Martin, T. Schöberl,

B. Rashkova, H. Clemens, and S. Mayer: Carbon distribution in multi-phase $\gamma$-TiAl based alloys and its influence on mechanical properties and phase formation. Acta Mater. 94, 205 (2015).
59. J. Wang and T. Nieh: The role of ledges in creep of TiAl alloys with fine lamellar structures. Acta Mater. 46, 1887 (1998).

60. M. Karadge, Y-W. Kim, and P.I. Gouma: Synergistic precipitation strengthening in TiAl alloys. Appl. Phys. Lett. 89, 181921 (2006).

61. P.I. Gouma, M.J. Mills, and Y-W. Kim: Characterization of the precipitation process in a TiAl-based alloy with carbon and silicon additions. Philos. Mag. Lett. 78, 59 (1998).

62. P.M. Hazzledine: Coherency and loss of coherency in lamellar Ti-Al. Intermetallics 6, 673 (1998).

63. J.J. Kruzic, J.P. Campbell, and R.O. Ritchie: Fatigue-crack propagation in gamma-based titanium aluminide alloys at large and small crack sizes. MRS Proc. 552, 1555 (1998).

64. R. Pippan, S. Wurster, and D. Kiener: Fracture mechanics of micro samples: Fundamental considerations. Mater. Des. 159, 252 (2018).

65. ASTM Standard E399-09: Standard Test Method for Linear-Elastic Plane-Strain Fracture Toughness $\mathrm{K}_{\mathrm{Ic}}$ of Metallic Materials, West Conshohocken, USA, (2009).

66. M.J. Blackburn: Some aspects of phase transformation in titanium alloys. The Science, 633 (1970).

67. S. Wurster, C. Motz, and R. Pippan: Characterization of the fracture toughness of micro-sized tungsten single crystal notched specimens. Philos. Mag. 92, 1803 (2012).

68. ASTM Standard E1820-13: Standard Test Method for Measurement of Fracture Toughness, West Conshohocken, USA, (2013).

69. J. Ast, B. Merle, K. Durst, and M. Göken: Fracture toughness evaluation of $\mathrm{NiAl}$ single crystals by microcantilevers-A new continuous J-integral method. J. Mater. Res. 31, 3786 (2016).

70. J. Ast, M. Ghidelli, K. Durst, M. Göken, M. Sebastiani, and A.M. Korsunsky: A review of experimental approaches to fracture toughness evaluation at the micro-scale. Mater. Des. 173, 107762 (2019).

71. R.E. Schafrik: Dynamic elastic moduli of the titanium aluminides. Metall. Trans. A 8, 1003 (1977).

72. J. Riedle, P. Gumbsch, and H.F. Fischmeister: Cleavage anisotropy in tungsten single crystals. Phys. Rev. Lett. 76, 3594 (1996).

\section{Open Access}

This article is licensed under a Creative Commons Attribution 4.0 International License, which permits use, sharing, adaptation, distribution and reproduction in any medium or format, as long as you give appropriate credit to the original author(s) and the source, provide a link to the Creative Commons licence, and indicate if changes were made. The images or other third party material in this article are included in the article's Creative Commons licence, unless indicated otherwise in a credit line to the material. If material is not included in the article's Creative Commons licence and your intended use is not permitted by statutory regulation or exceeds the permitted use, you will need to obtain permission directly from the copyright holder. To view a copy of this licence, visit http://creativecommons.org/licenses/by/4.0/. 